\title{
Provocações para uma sociologia da sexualidade: Sistemas, linguagem, amor
}

\author{
Provocations for a sociology of sexuality: Systems, language, love
}

\author{
Marcelo Augusto de Almeida Teixeira
}

Resumo O artigo busca pensar, a partir de uma sociologia da sexualidade, as provocações epistemológicas propostas por Judith Butler e Niklas Luhmann, sobretudo os pressupostos de que o sujeito é "inexistente", vindo a existir por meio da linguagem, e de que a sociedade existe apartada do sujeito - sendo composta por comunicações. O texto discorre sobre os modos pelos quais a sociologia refletiu o corpo sexuado, passando pela polarização entre essencialistas/construcionistas, até as recentes tentativas de síntese entre esses polos, ilustrada com uma topologia baseada na faixa de Mobius lacaniana. O objetivo é ilustrar a importância dada à linguagem na constituição de corpos, sexualidade e valor de "humano", a partir do exemplo de "crianças-feras" e do conceito butleriano de "abjeto". Por fim, considera-se o Amor a partir de uma perspectiva sistêmica, com contribuições da Neurociência, concluindo que a Sociologia da Sexualidade se beneficia do sistema luhmanniano: o sujeito se configura mais autônomo em seu contexto social, psíquico e biológico e nos sistemas da sexualidade. Nesse cenário, não só o sujeito se torna central, porquanto seu próprio corpo físico seja a interseção de sistemas sociais, psíquicos e biológicos, mas também a sexualidade se torna cada vez mais autônoma, estetizada, atomizada a uma questão de escolha individual, com repercussões políticas, espaciais, corporais e sociais.

Palavras-chave Sociologia da Sexualidade; Sistemas; Linguagem; Amor; Sujeito.

Abstract The purpose of this article is to think, with from a Sociology of Sexuality, the epistemological provocations proposed by Judith Butler and Niklas Luhmann, mainly the assumptions that the subject does not exist (yet comes into existence through language) and that society exists apart from the subject (being composed

of communications). The article discusses how Sociology thought the sexed body, passing through the polarization between essentialists and constructionists, until recent attempts of synthesis between these poles, illustrated by a topology based on the lacanian Mobius strip. The article proposes to illustrate the importance given to

a Graduado em Arquitetura e Urbanismo pela Universidade de Brasília, Mestre em Teoria e História da Arte pela Universidade de Brasília e, atualmente, doutorando em Sociologia pela mesma instituição e professor de Teoria da Arquitetura no Centro Universitário do Distrito Federal. 
language in the constitution of bodies, sexuality and the value of "human", from the example of "feral children" and the Bluterian concept of "abject". Finally, we consider Love from a systemic perspective, with contributions from Neuroscience, concluding that Sociology of Sexuality benefits from the Luhmannian system: the subject becomes more autonomous in front of his social, psychological and biological contexts and sexuality systems. In this scenario, not only the subject becomes central, since his own physical body is the intersection of social, psychological and biological systems, but also human sexuality becomes increasingly autonomous, aestheticized, atomized into a matter of individual choice with political, spatial, bodily and social repercussions. Keywords Sociology of Sexuality; Systems; Language; Love; Subject.

\section{INTRODUÇÃO}

"A sociologia da sexualidade não existe". Com tal afirmação, Michel Bozon (2004, p. 13) provoca a reflexão sobre as intersecções entre o social e a sexualidade humana. Na contemporaneidade, essas intersecções se tornam importantes para a concepção de sujeito: para Alain Touraine (AdELman, 2004), a sexualidade é inseparável do sujeito, já que a primeira seria a associação do segundo mais a categoria "sexo". Dessa forma, pensar o sujeito implicaria pensar também não só sobre sua sexualidade e seu lócus social, mas sobre o seu corpo, já que esse não seria apenas uma "tabula rasa biológica”, mas uma "interface entre o interpessoal e o intrapsíquico" (Grosz, 1994, p. 18; GAGNON; Simon, 2011, p. 307). Corpo, sujeito, sexualidade e sociedade conformariam uma equação da qual subjetividade e identidade seriam derivadas e que nos remetem a questionamentos presentes desde as origens da Sociologia, como o que pergunta se a sociedade produz a si mesma ou, segundo Simmel (2006 [1917], p. 15), "significa a interação psíquica entre indivíduos”. Porém, na pós-modernidade, quando se questiona a própria noção de sujeito e mesmo sua participação na sociedade, a fixidez das identidades e a própria materialidade do sexo, como definir o sujeito nessa equação?

O sujeito seria um somatório de consciências e seu corpo físico um suporte biológico e social. Para Paulo Ghiraldelli Jr., existem quatro formas gerais de consciência, que se somam na constituição do sujeito: o "eu”, a "pessoa", o "cidadão" e o "sujeito epistemológico", relacionados respectivamente ao corpo (físico) e à identidade (psíquica), à moralidade, à política e, por fim, ao intelecto e à linguagem (GhirAldELLi JR., 2007, p. 35). Na contemporaneidade, os ideários modernos que sustentavam o sujeito epistemológico, a pessoa e o cidadão entraram em crise e, sem ter onde se ancorar, a identidade individual passou a privilegiar o corpo físico 
como repositório do eu e localização do sujeito (GHIRALDELLI JR., 2007, p. 45). Além disso, os processos contemporâneos de individuação libertam ainda mais o sujeito das estruturas sociais remanescentes da modernidade, tornando-o mais livre para escolher suas narrativas de vida e seus comportamentos, ainda mais autônomo frente às suas condições sociais, psíquicas e naturais (LASH, 1997, p. 135-145). Mais livre até mesmo para mudar sua condição sexuada inata, reconstruir seu corpo físico, sua face, sendo mais instável, portanto, tanto em sua ontologia quanto em sua própria corporalidade.

O corpo torna-se, então, importante ancoragem do sujeito e sítio de inscrições do mundo social: segundo Bourdieu, "o corpo está sujeito a um processo de socialização cujo produto é a própria individuação, a singularidade do 'eu’ sendo forjada nas e pelas relações sociais" (BouRdieu, 2001, p. 163; aspas no original). Ora, se para Touraine é impossível pensar o sujeito sem pensar na sexualidade, para Ghiraldelli o corpo está indissociável do sujeito e para Bourdieu o corpo é produto e produtor da socialização e do eu, logo, é possível admitir que sexualidade, corpo, sujeito e o social estão intrinsecamente conectados. Tal admissão traz consigo o entendimento de que esse ente chamado "sujeito" - ainda que mais livre em relação aos seus contextos sociais, psíquicos e biológicos - é, ao mesmo tempo, somatório e somatização de causas e efeitos desses mesmos contextos.

O sujeito se depara, atualmente, com dois desafios teóricos para uma sociologia da sexualidade: primeiro, o pressuposto de que o próprio sujeito seria inexistente (porém, vindo a existir por meio de um quadro linguístico valorativo); segundo, a suposição de que a sociedade existe independente do sujeito, criando a si própria. Judith Butler (1993) e Niklas Luhmann (2009) exemplificam respectivamente tais desafios. Pensar a sexualidade sociologicamente, a partir do pensamento de Butler e Luhmann, oferece pelo menos quatro provocações: como pensar a sexualidade em uma sociedade na qual o sujeito pode ser inexistente ou formado por meio de marcos linguísticos e/ou níveis de desqualificação? Seria possível entender a sexualidade como um sistema à parte do sujeito, sendo autopoiética, autorreferente e criada por meio da linguagem e da comunicação? Se sim, quais as consequências de se entender a sexualidade apartada do sujeito, já que essa deixa de ser uma propriedade e manifestação distintiva daquele? Afinal, que lugar o Amor ocupa em uma sociedade sem indivíduos e no interior da sociologia da sexualidade? Pensar sociologicamente a sexualidade pelas lentes oferecidas por Butler e Luhmann radicaliza não só o costumeiro debate desempenhado pelas teorias essencialistas e construcionistas da sexualidade humana, mas inclusive a discussão acerca do papel da linguagem, dos afetos e do corpo para uma sociologia da sexualidade. 
O presente artigo será dividido em quatro partes. Na primeira, apresenta-se um panorama sociológico da sexualidade desde o início da crescente liberação da sexualidade humana dos controles institucionais (igreja, família, etc.), a partir dos séculos XVIII e XIX, e sua constituição como um sistema autônomo no qual discursos especializados, urbanização e diferenciação social influenciaram, configurando um contexto em que a noção de sexualidade se entrelaça com a própria modernidade. Nesse sentido, aponta-se de que maneiras a Sociologia pensou o corpo sexuado, desde suas origens como disciplina, passando pela polarização entre essencialistas e construcionistas, até recentes tentativas de síntese entre esses polos, como a Teoria dos Campos Sexuais (TCS), que ilustro com um modelo gráfico baseado na faixa de Mobius, proposta por Anne Fausto-Sterling (2000) e Elizabeth Grosz (1994; 2001), em suas visões de sujeito e sexualidade. Na segunda parte, tento articular o pensamento de Butler e Luhmann, com contribuições dos construcionistas Deborah Cameron e Don Kulick (2003) - que enfatizam o papel da linguagem na construção da sexualidade humana - com o propósito teórico de pensar uma sociologia da sexualidade em uma "sociedade sem sujeitos", feita por meio de comunicações. Na terceira parte, analiso a categoria Amor desde uma perspectiva híbrida, a partir da Teoria dos Sistemas e das contribuições da Neurociência e da Sexologia, passando por Agnes Heller (1993 [1980]), objetivando entender o fenômeno do Amor mais como um fato social do que como um sentimento inato moralmente superior e separado da sexualidade. Nessa medida, o Amor, tanto em sua psico-bio-sociogênese quanto em seus limites, é mediado socialmente e enquadrado pela linguagem. É necessário dizer que não separo, neste artigo, o Amor da sexualidade, já que para Luhmann (2010) um está no alicerce do outro. Por fim, concluo que, a partir de uma perspectiva sistêmica, a sociologia da sexualidade só teria a ganhar ao encarar a sexualidade enquanto sistema autopoiético e autorreferente, diante do qual o sujeito se conforma mais autônomo frente ao seu contexto social, psíquico e biológico.

A hipótese deste artigo é de que não só o sujeito se torna central nesse cenário, posto que seja seu próprio corpo físico a interseção de sistemas sociais, psíquicos e biológicos, como a sexualidade humana torna-se cada vez mais autônoma, estetizada, atomizada e mais uma questão de escolha individual, com repercussões políticas, espaciais, corporais e sociais, do que propriamente inata ao sujeito.

\section{PENSANDO UMA SOCIOLOGIA DA SEXUALIDADE}

A partir do final do século XIX, a sexualidade humana se conformou em um campo de crescente autonomia, com seu próprio corpo de "especialistas", "auto- 
ridades" e discursos autorizados, capaz de gerar efeitos subjetivos, identitários e materiais (nos corpos e espaços físicos). Segundo alguns autores, as origens desse movimento à autonomia já poderiam ser observadas nos séculos XVII e XVIII (Dabhoimala, 2013; Luhmann, 1998; Giddens, 1993; Hunt, 1996). Para Norbert Elias (1993), por exemplo, os rigorosos códigos sexuais aristocráticos da Europa feudal passaram por um processo de relaxamento durante a ascensão burguesa. Mas, é apenas no século XIX, com a crescente individualização proporcionada pela maior divisão social do trabalho, urbanização e aumento populacional que a sexualidade passa a ser menos sujeita às vigilâncias e imposições da comunidade e do poder de instituições (como a família e a igreja), tornando-se polimorfa. Além disso, os discursos médico-jurídicos e criminais, que emergiram durante o século XIX, também foram basilares na conformação da sexualidade moderna. A própria "modernidade" estaria imbricada, então, na noção de "sexualidade" e em categorias identitárias aí incluídas, como "homossexualidade" (BECH, 1997; HAwkes, 1996). Assim, modernidade e sexualidade estariam entrelaçadas na constituição de corpos, personas, instituições e mesmo nos espaços físicos.

Com a crescente autonomia iniciada nos séculos XVIII e XIX pavimentou-se o caminho para que a sexualidade contemporânea fosse entendida como multiplicidade de "campos sexuais" - no sentido bourdieusiano - relativamente autônomos, progressivamente atomizados e especializados, nos quais se envolvem tanto o biológico quanto o social, tanto o indivíduo quanto o coletivo, com repercussões tanto sobre o sujeito quanto nas interações sociais (GreEn, 2014). Na contemporaneidade, entende-se que a sexualidade é socialmente construída, permeada por discursos oriundos de diversas fontes (da política, pornografia, religião, entre outras), e transversal a variadas categorias identitárias (como classe, raça, idade, gênero e orientação sexual). Entretanto, até recentemente, a Sociologia encarou a sexualidade humana como um dado natural, sem interferência do social: apesar de abordarem o ser humano como socialmente construído, resultado de seu tempo e de seu lócus social, os sociólogos clássicos pouco afirmaram sobre o corpo e sua condição sexuada na modernidade (SEIDMAN, 1996).

Fundamental para uma mudança de percepção foram os questionamentos apresentados pelas feministas e liberacionistas gays e lésbicos, os quais desafiaram os discursos médico-científico-jurídicos vigentes, que substancializavam a identidade homossexual e a condição da mulher. Apesar de questionamentos a tais discursos já serem conhecidos desde o século XIX, foi a partir da década de 1960 que se tornaram mais influentes nas Ciências Sociais. Com a Teoria "Queer", a partir dos anos 1990, a sexualidade humana passou a ser entendida também como 
resultado de marcos identitários formados por meio da linguagem, que enquadra tudo o que sabemos acerca de desejos, corpos, identidades, práticas e sexualidades. O sujeito, nesse cenário, passa, paradoxalmente, tanto a ser valorizado em sua corporalidade quanto a ser desmontado como uma construção resultante de estruturas linguísticas preexistentes.

A demora em minimizar as determinações biológicas da sexualidade por parte dos sociólogos pode ser explicada por serem as subjetividades e práticas sexuais um assunto difícil dentro das Ciências Sociais (GIDDENS, 2012). O próprio conceito de sexualidade é fugidio, abarcando todos os aspectos eroticamente relevantes, como desejos, práticas, identidades, relacionamentos (Sсотт, 2010), além das presumidas determinações biológicas, o que faria de uma sociologia da sexualidade um desmotivador "trabalho infinito de contextualização social e cultural" (Bozon, 2004, p. 151). Em tal contextualização, importaria, para o sociólogo, compreender os processos pelos quais não só os parâmetros socialmente aceitos são conformados, mas também entender que as noções de "prazer sexual" e "desejo erótico" são socialmente construídas em diversos níveis, e que a interação sexual é "a mais corpórea das interações sexuais” (ColLins, 2004, p. 226; GreEn, 2014). Percebe-se, então, que pensar a sexualidade do ponto de vista sociológico é adentrar em uma arena onde embates entre diversos posicionamentos ocorrem.

Entre tais embates, aquele desempenhado entre as perspectivas essencialistas e construcionistas da sexualidade dominou, não só as Ciências Sociais, mas também outros campos epistemológicos, como a Biologia e o Direito. Para os essencialistas, a identidade sexual de um corpo está atavicamente impregnada pela sua materialidade, pelo sexo cromossômico, pelas características sexuais dadas ao nascer, pela química hormonal. Em suas modalidades mais extremas, o essencialismo sugere reconhecermos que o controle sobre as ações tem bases inteiramente neurobiológicas, sendo o "livre-arbítrio" algo físico (BERING, 2013, p. 85). Já para os construcionistas, a sexualidade é uma produção de longo prazo, variável no tempo e no espaço, para a qual o corpo é apenas um suporte para uma construção histórica que abarca outras construções (como identidades, prazer sexual, desejo erótico), sendo a identidade sexual, portanto, "um complexo resultado de desenvolvimento, a consequência de um processo interativo de etiquetagem social e auto-identificação" (Epstein, 1996, p. 151). Para construcionistas como Deborah Cameron e Don Kulick, a linguagem exerce poderosa influência sobre a construção da sexualidade, pois é pela linguagem que o entendimento sobre a sexualidade é formado e mediado (CAmeron; Kulick, 2003, p. 12). Em um exemplo extremo de construcionismo, Butler (1993) sugere que a própria materialidade do sexo seria 
discursiva, produzida por meio de demarcações linguísticas. Dessa forma, ambos os posicionamentos repercutem na noção de sujeito, ora reduzindo sua autonomia frente às imposições biológicas e químicas, ora definindo-o e diluindo-o como um efeito da linguagem.

Entretanto, surgem posições que visam ocupar um terceiro espaço, no qual a sexualidade é entendida ao mesmo tempo como social e biológica, também repercutindo na noção de sujeito. Anthony Giddens, por exemplo, sugere que a sexualidade é uma “interação complexa entre fatores biológicos e sociais”, ainda não compreendida em sua totalidade (GIDDEns, 2012, p. 415). Para Gail Hawkes, a sexualidade é "tanto uma ficção quanto uma realidade, tanto uma criação artificial quanto uma experiência vívida” (HAWkes, 1996, p. 8).

Uma proposta teórica que tenta articular as perspectivas construcionistas e essencialistas da sexualidade é herdeira de Pierre Bourdieu, a Teoria dos Campos Sexuais (TCS), a partir da qual a sexualidade é entendida como construção social, derivada de preferências eróticas particulares do sujeito, corporificadas, socializadas e apreendidas dentro de um "campo sexual" autônomo. O sujeito é posicionado no campo conforme critérios específicos de "desejabilidade”, dentro de "estruturas de desejo" que vinculam formas de "capital erótico" e produzem "habitus eróticos" (GreEN, 2014). Os campos sexuais são configurados em um continuum entre níveis intrapsíquicos (idiossincrasias eróticas do sujeito) até processos macroestruturais que porventura impactam na sexualidade individual e coletiva.

Assim, para a TCS, não há limites entre a somatização individual e a socialização dos desejos eróticos; entre a sexualidade coletiva e a particular; entre o social e o biológico. Similarmente, para a bióloga Anne Fausto-Sterling, a sexualidade seria um fato somático criado por efeitos culturais, sugerindo, ainda, erodir as distinções entre o corpo físico e o social (FAusto-STERling, 2000). Aponta-se, então, para um entendimento no qual a sexualidade é, ao mesmo tempo, discursiva e vivida na pele, imbricada tanto no biológico quanto no social, com efeitos na materialidade do corpo e, também, nos planos abstratos da experiência humana, que abarcariam desde processos macroestruturais até psíquicos e biológicos.

De acordo com Fausto-Sterling (2000, p. 24), pode-se entender a sexualidade como uma faixa de Mobius (Figura 1): um desenho no qual o interno se torna externo e o exterior se torna interior em um movimento contínuo. A imagem da faixa de Mobius é também utilizada pela filósofa feminista Elizabeth Grosz (1994; 2001) que, por sua vez, dialoga com o pensamento lacaniano em suas obras de modo a ilustrar sua concepção de sujeito e sexualidade: uma "rotação de formas impossíveis em espaços ilegíveis", na qual inflexões entre o corpo e a mente, o 
interior físico e o exterior corpóreo se tornam iguais em um movimento de torção (Grosz, 2001, p. 32; 1994, p. XII). A utilização da faixa de Mobius - ou contrabanda lacaniana - é útil por esta não ser bilateral e orientável, e sim unilateral, contínua e não direcional. Ou seja, na contrabanda, não existe interior e exterior, dentro e fora, esquerda e direita, movimentos para frente ou para trás. Conforme diz Lacan, na contrabanda, "seu direito continua seu avesso" (LACAN, 1988 [1964], p. 148). Para Fausto-Sterling (2000) e Grosz (1994), a sexualidade é indistintamente biológica, social e psíquica, em um contínuo movimento que não reconhece fronteiras nem delimita lados.

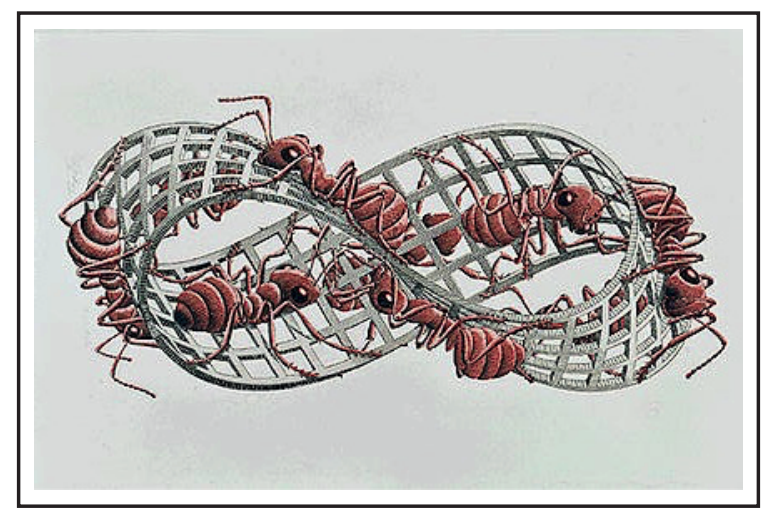

Figura 1. Faixa de Mobius. Fonte: <http://www.mcescher.com/gallery/recognition-success/mobius-strip-ii/>.

Entretanto, uma questão permanece nessa síntese entre o construcionismo social e o essencialismo da sexualidade: onde está o sujeito? Para Agnes Heller, somos cindidos entre a "essência muda da espécie" e o "caráter próprio da espécie", ou seja, respectivamente, entre o organismo e suas atávicas peculiaridades e o que é externo e anterior a nós, como a cultura, a linguagem e o social (HeLler, 1993, p. 30-31). Para a autora, tal cisão nunca pode ser suturada por completo, e a busca contínua de uma solução é o que conforma a existência, o que constitui o "Ego".

Desse modo, chega-se a um impasse: há pontes possíveis entre os hiatos existentes entre a materialidade biológica, a realidade psíquica e o mundo social? Na ilustração sugerida por Grosz (1994) e Fausto-Sterling (2000), o sujeito é o resultado das torções contínuas entre o psíquico, o social e o biológico, sendo difícil precisar quando um começa e o outro termina. Mas, se para Vincent de Gaulejac (2013), "não se pode pensar a questão do sujeito sem inscrevê-lo em uma dupla determinação: social e psíquica”(DE GAULEJAC, 2013, p. 70), para Luhmann, "quem considera seriamente o ser humano como uma entidade concreta e empírica formada física, química, orgânica e psicologicamente, não pode conceber o indivíduo como parte do sistema social” (Luhmann, 2009, p. 59). 
Uma ilustração possível para amenizar esse impasse seria abstrair o sujeito como uma tripla faixa de Mobius (a torção contínua entre o social, o psíquico e o biológico), que contém uma faixa dupla na qual se ilustra as torções entre o social e o indivíduo, entendido, aqui, por uma perspectiva luhmanianna: como o conjunto do sistema biológico e psíquico (Figura 2). Nessa topologia, a ilustração da tripla faixa visa demonstrar um sujeito compreendido como o resultado de um continuum de influências mútuas entre suas determinações biológicas, seu sistema psíquico, seu lócus social e vice-versa. A ilustração parece adequar-se à concepção de sujeito da "modernidade reflexiva" (BEck, GidDEns; LASH, 1997), na qual o sujeito se reveste de maior autonomia frente ao seu entorno social, natural e psíquico, além de maior individualização (LASH, 1997), sendo a sexualidade contemporânea mais uma “tomada de decisão" do que dada naturalmente (GIDDENs, 1997).



Figura 2. A tripla faixa de Mobius. Fonte: Elaborada pelo autor

\section{A PROVOCAÇÃO DOS SISTEMAS E DA LINGUAGEM: UMA SOCIOLOGIA DA SEXUALIDADE SEM SUJEITOS?}

Na pós-modernidade, procurou-se a dissolução de um sujeito humano, por meio da primazia de estruturas sociais e linguísticas. Segundo Margareth Archer (2000), o pós-modernismo nega ao sujeito humano qualquer forma de maestria sobre as formas e o desenvolvimento da sociedade. Como exemplo de tal negação, Niklas Luhmann (2009) propõe um conceito de sociedade radicalmente anti-humanista e construtivista, sob o primado da comunicação, na qual o corpo humano é deslocado para fora da sociedade. Na Teoria dos Sistemas de Luhmann é possível localizar três sistemas: social, psíquico e biológico. O corpo humano é considerado como "sistema biológico", por sua vez "acoplado" ao sistema "psíquico". 
A união analítica do sistema psíquico e biológico "representa aquilo que a tradição sociológica tem chamado de indivíduo, de pessoa, de sujeito (tanto na dimensão física quanto na psíquica)" (Rodrigues; Neves, 2012, p. 43). Entretanto, na teoria sistêmica luhmanianna, o indivíduo é apartado da sociedade: "a constituição biológica e psicológica do ser humano não faz parte dos sistemas sociais e sistemas psíquicos", sendo necessário uma "separação radical entre sistemas sociais e sistemas psíquicos” (LuHmann, 2009, p. 260).

Os sistemas são cerrados, autorreferentes e autopoiéticos (que criam a si mesmos). Dado sua clausura autopoiética, os sistemas psíquicos não podem se comunicar com a sociedade e a única ponte entre ambos é a linguagem, única que possibilita a comunicação (IzUQuizA, 2008). O sujeito, então, por uma perspectiva luhmanianna, é um sistema cerrado, autorreferente e que cria a si mesmo, conectado ao social por meio da linguagem. Aqui, a sociedade não abarca o biológico e o psíquico individual, ao ser composta apenas por comunicações. Como pensar, a partir dessa perspectiva, em sexualidade e sujeito?

Sexualidade, em uma perspectiva sistêmica, é também uma forma de comunicação, sendo assim integrada nos processos que formam a sociedade e sendo um de seus inúmeros subsistemas (Luhmann, 2010). Luhmann afirma existirem "mecanismos simbióticos" conectados ao biológico e ao psíquico, que formam a base necessária para comunicações; entre esses mecanismos está a sexualidade (Luhmann, 2010, p. 27). A relação íntima, o amor e a sexualidade passam a ser relações entre sistemas: entre dois sistemas individuais e o entorno. Nessa medida, são importantes as "interpenetrações interpessoais" que, para Luhmann, não se trata de dois sistemas individuais que, ao tornarem-se amantes, tornam-se um só; mas, sim, que mantêm sua individualidade e sua separação com o entorno, respondendo reciprocamente aos mesmos estímulos, sendo que a comunicação é algo fundamental para a manutenção dessa reciprocidade. Uma vez cessada a comunicação, os sistemas colapsam. Dessa forma, deve-se entender a interação sexual, a "mais forte copresença corporal" (Collins, 2004, p. 231), também como operação de linguagem que "acopla" sistemas individuais e sociais.

O "acoplamento" entre sistemas, que Luhmann denomina de "estrutural", se dá pela linguagem, ou seja, "é através da linguagem que o acoplamento estrutural ordinário entre sistemas de consciência e sistemas de comunicação se torna possível” (Luhmann, 2009, p. 281). Tanto o sistema psíquico quanto o social só operam pelo meio do "sentido", sendo ele uma operação de comunicação. Assim, é por meio da linguagem - que proporciona operações de sentido - que o indivíduo (um sistema composto de psíquico e biológico) se acopla ao social: o eu, o 
sujeito e sua sexualidade, a partir de uma perspectiva sistêmica, são sistemas que surgem por meio de comunicações. Aqui, há uma similaridade entre Luhmann e Butler: o que está em questão são operações linguísticas e denominações que acabam por formular algo que se assemelha a um "eu". Para Butler, não existe um "eu" atrás dos discursos e dos atos de fala; ao contrário, esse "eu" só aparece após a linguagem, após ser interpelado por significados que precedem sua existência (Butler, 1993, p. 171; em livre tradução). Segundo a autora, o sujeito é um "acontecimento linguístico" sobre o qual a linguagem tem efeitos na própria materialidade corpórea, ao estabelecer, mediar, inscrever e legitimar códigos entre o social e a carne. Assim, o que concebemos como sexualidade, corpo e sujeito são efeitos de operações comunicativas que estabelecem e estigmatizam, dão vida ou mortificam, criam interiores e exteriores.

Tais operações se inserem na materialidade do corpo que, segundo Butler (1993), é um processo de demarcação de limites e formas. Reforço tal aspecto com Bourdieu, para quem "as injunções sociais mais sérias se dirigem ao corpo" (Bourdieu, 2001, p. 172). Na mesma direção de Butler, o crítico literário Samuel Delany afirma que a linguagem não molda só o social, mas também o que se convencionou chamar de "realidade", sendo capaz, portanto, de criar "categorias ontológicas" que acabam por dar vida ao que denominam (Delany, 1999, p. 189). De acordo com Delany, somos "interpelados" - no sentido althusseriano do termo - em nossas sexualidades, pela linguagem e pelas categorias ontológicas. Se, para Luhmann, "na nomeação das coisas [...] está contido um ato de criação do ser humano" (Luhmann, 2009, p. 288), para Butler e Delany a nomeação das coisas cria, inclusive, o sujeito, seu corpo físico e seu exterior. Conforme afirmam Cameron e Kulick (2003), as sexualidades não fazem sentido fora dos discursos linguísticos que as denominam, que as criam, que as definem, ou seja, fora das categorias ontológicas criadas pela linguagem. Ainda, Cameron e Kulick (2003) apontam para o entendimento de que a sexualidade é legível, comunicada, mediada por atos de fala que moldam o entendimento enquanto seres sexuados. Dessa forma, uma linha condutora entre os autores citados acima aponta para o entendimento de que não haveria sexualidade possível fora dos esquemas de comunicação e de que esses esquemas se inscrevem no corpo.

"Sem a sociabilidade humana, a sexualidade humana não pode se desenvolver" afirma Anne Fausto-Sterling (2000, p. 23). De fato, na literatura sobre "crianças-feras", aquelas criadas supostamente por animais ou em extremo isolamento do convívio humano, destaca-se a ausência de linguagem e de sexualidade, somada a uma diferença dos órgãos genitais e da postura corporal, em relação aos das 
crianças socializadas (ZingG, 1940; CANdLAND, 1995; Lehman, 2007; Davis, 2007). Para Michael Newton, essas crianças são existências fora dos esquemas de comunicabilidade, logo, "fora de qualquer sociedade", levando-nos a perguntar sobre o papel da linguagem na formação de nossa humanidade e o que nos faz reconhecer um ser humano como humano (NewTon, 2002, p. 48), já que só nos tornamos humanos quando entramos na dimensão do "caráter próprio da espécie", ou seja, quando adquirimos cultura, somos socializados e temos uma linguagem. Por isso um ser humano criado entre cavalos não pertenceria à nossa espécie (HelLer, 1993, p. 30-31). Intocadas pelo caráter próprio da espécie, incapazes de utilizar as palavras dos humanos socializados para comunicar e mediar seus entendimentos sobre a própria sexualidade, essas crianças isoladas de fatores sociogênicos não teriam como construir sexualidades e nem o próprio entendimento acerca de seus desejos e de si enquanto sujeitos dotados de um corpo sexuado. Por uma perspectiva sistêmica, sem a linguagem para acoplar seus sistemas biológicos e psíquicos (o sujeito) aos sistemas da sexualidade, essa não seria possível. Aqui, a ausência da linguagem e, por consequência, da sexualidade, nega a alguns humanos o reconhecimento como tal.

Entretanto, a linguagem também faria de alguns sujeitos (e de seus corpos) mais legivelmente "humanos" do que outros. Esta é uma das premissas de Judith Butler (1993), para quem os sujeitos e seus corpos podem ou não habitar o "exterior" de uma "matriz heterossexual", uma matriz "exclusionária", que expulsa os indivíduos que não se inscrevem nos códigos inteligíveis de masculinidade, feminilidade e heterossexualidade. Nessa matriz, corpos só fazem sentido, ou seja, só são inteligíveis, legítimos e legíveis quando sexo, gênero e desejo são coincidentes e coerentes para um quadro heterossexual (BRADY; SchiRATO, 2011). Todos os outros corpos que escapam desse quadro são colocados em um exterior "inabitável". Butler (1993) denomina esse exterior de "constitutivo" (constitutive outside), um exterior "abjeto" que se torna o interior constitutivo desses sujeitos não inteligíveis. Nas palavras da autora: "o abjeto aqui designa precisamente aquelas zonas 'inabitáveis' e 'inviáveis' da vida social que, entretanto, são densamente povoadas por aqueles que não gozam do status de sujeito" (BuTLER, 1993, p. XIII; em livre tradução). Ainda, Butler considera que justamente a exclusão é fundamental na conformação corpórea e subjetiva, tanto do corpo ajustado à matriz quanto do morador da zona abjeta, sendo tal disposição dos corpos uma operação de poder. Retomando Norbert Elias: "do mesmo molde social emergem seres humanos mais ou menos estruturados, tanto os 'bem ajustados' como os 'desajustados', num espectro muito grande de variedades" (EliAs, 1993, p. 204; grifos no original). 
Essa exclusão, em Butler, pode ser relacionada ao conceito de "interpenetração de sistemas", definido por Luhmann: um sistema disponibiliza sua própria complexidade para que outro se construa, sendo que "o sistema receptor exerce também uma influência retroativa sobre a formação das estruturas do sistema penetrador, intervindo nele, portanto, de duas formas: a partir do interior e do exterior" (Luhmann, 2009, p. 267). Ao excluir, ao observar (e, por consequência, distinguir) os corpos desajustados, adentra-se em uma operação luhmanianna, tendo em vista que "os sistemas constituem-se a si mesmos ao constituir os elementos que os constituem, ou seja, ao selecioná-los os formam como elementos no ato de distingui-los de um entorno" (RASCH, 2000, p. 46-47). Nesse sentido, por meio de distinções linguísticas, os sujeitos são selecionados e constituídos como elementos de dois sistemas e dois exteriores ao mesmo tempo: o dos corpos ajustados e o dos abjetos. Um não se constrói sem o outro. Ainda, por meio de demarcações linguísticas, por discursos que autorizam e/ou proíbem, o sujeito é então modelado, sendo principalmente a internalização do que é proibido e abjeto o que se torna primário na conformação de uma identidade sexual e de gênero (SALIH, 2012, p. 79). Não só a interiorização do abjeto se torna importante para o sujeito, mas também as experiências nas quais os indivíduos são feridos "na compreensão positiva de si mesmos", como rebaixamentos morais desses indivíduos e grupos sociais (HonNETH, 2003, p. 213-217). Com isso, torna-se inseparável do surgimento de um sujeito a linguagem pela qual este é enquadrado em categorias ontológicas - normativas e valorativas - com repercussões na sua própria corporalidade e sobrevivência física.

Se, na pós-modernidade, tentou-se a dissolução do sujeito por meio da preponderância da linguagem e o apartado dos rumos da sociedade, o mesmo sujeito poderia ter-se tornado mais autônomo frente aos constrangimentos sociais e biológicos em uma sociedade da qual não faria parte. Se, para Giddens (1997), o sujeito dota-se de maior autonomia frente aos seus constrangimentos, para Luhmann:

Graças à distinção entre sistema e meio, é possível conceber o homem como parte do meio social, de maneira mais complexa e, ao mesmo tempo, mais livre, do que se ele fosse concebido como parte da sociedade, uma vez que o meio, comparativamente ao sistema, constitui o campo de distinção de maior ou menor ordem. Assim, concedem-se ao ser humano mais liberdades em relação ao seu meio; sobretudo, certas liberdades de comportamento irracional e imoral (LuHMANN, 2009, p. 260). 
Dessa forma, pensar em uma sociologia da sexualidade em uma sociedade na qual os sujeitos são apartados não só nos leva a considerar a sexualidade como sistema autônomo, autorreferenciado e autopoiético, que cria sua própria estrutura e elementos, que se acopla aos indivíduos por meio da linguagem, mas também que proporciona maior reflexividade aos sujeitos, que podem inclusive mudar sua conformação genital nata e escolher entre diversos subsistemas de sexualidade disponíveis em uma sociedade cada vez mais diferenciada. Ao mesmo tempo, da mesma maneira que as categorias ontológicas permanecem como produtoras de subjetividades, identidades sociais, corpos e sujeitos, inserindo-os em categorias linguísticas preexistentes que têm o poder de criar o que nomeiam, o sujeito teria mais reflexividade frente a essas categorias, podendo mesmo recusá-las, estetizá-las, transitar entre várias, e dotá-las de força política.

\section{A PROVOCAÇÃO DO AMOR: DENTRO OU FORA DE UMA SOCIOLOGIA DA SEXUALIDADE?}

Para estudar o Amor a partir de uma perspectiva sociológica, é preciso confrontar pressupostos socialmente aceitos que o consideram como sentimento universal e anistórico. Conforme um popular ditado judaico: "O Amor não é apenas um sentimento, é acima de tudo uma ação" - acrescentando, uma “ação afetiva”, nos moldes weberianos -, no qual o sentido não está no resultado final, mas na própria ação (WEBER, 2012, p. 15). Para Luhmann, o Amor não é nem um fenômeno natural nem uma ideia moral eternamente verdadeira e constante historicamente, mas um fato social (LuHMANn, 2010) e, sendo assim, exterior ao sujeito.

Desta maneira, por uma perspectiva sociológica, pode-se entender o Amor como sendo ao mesmo tempo fato social e ação afetiva, envolvidos em uma interação microssocial entre dois sujeitos e um processo social mais abrangente, simultaneamente orientado publicamente e privativamente, visando à cooperação, à autorrealização e ao bem-estar dos sujeitos envolvidos - podendo ou não envolver a sexualidade. Entretanto, seguirei neste artigo a posição de Luhmann, para quem a sexualidade está nos fundamentos do Amor (Luhmann, 2010, p. 47), não separando as perspectivas sociológicas sobre o Amor de uma sociologia da sexualidade, já que o Amor seria "indistinguível da solidariedade e ligação proporcionadas por algumas relações sexuais intensas não amorosas" (ColLıNs, 2004, p. 237).

O Amor é concebido tanto como sentimento (experimentado privadamente) quanto como emoção (socialmente condicionada). Para Agnes Heller, as idiossincrasias biológicas e sociais determinam como somos implicados em um sentimento 
(HeLler, 1993, p. 17); se entendermos aqui o Amor como tal, logo este será constrangido por fatores bio e sociogênicos. De fato, a Neurociência aponta para um entendimento de que o Amor se torna "carne" por meio de uma complexa interação entre hormônios - como oxitocina e vasopressina, que regulam os vínculos afetivos humanos (Mlodinow, 2013, p. 113) - entre as sinapses biológicas e as "sociais" que ocorrem durante as interações face a face (Cozolino, 2014, p. XV). Entre as idiossincrasias sociais que determinam as implicações do sujeito com o Amor, encontra-se a linguagem, que ao nomear reações hormonais como "Amor", leva o sujeito que nomeia a se implicar em uma série de imposições que o Amor, como fato social, carrega consigo. Por esse caminho, o Amor seria simultaneamente algo independente da vontade humana e também resultado de condições sociais, psíquicas, físicas e biológicas diversas.

Além de ser um fato social múltiplo, o Amor pode ser considerado como um meio de comunicação pela Teoria dos Sistemas, já que para Luhmann (2010) o Amor é uma forma de comunicação dependente de estruturas sistêmicas e na qual outras formas não verbais de se comunicar são indispensáveis. Já para Judith Butler, o Amor assemelha-se a uma troca entre dois indivíduos na qual os desejos são mais ou menos legíveis, sendo essa troca impactada por suas histórias pessoais (BUTLER, 2002). Para Henning Bech, o Amor é uma forma de comunicação, principalmente verbal, orientada para o entendimento comum entre dois indivíduos em relação às suas qualidades intrínsecas e de suas narrativas biológicas e históricas (BECH, 1997, p. 141-147). Assim, em comum aos três autores, o Amor pode ser entendido como uma questão de linguagem, na qual a legibilidade de si mesmo, dos desejos mútuos, do Outro e do seu corpo são dependentes tanto das narrativas individuais quanto de estruturas sistêmicas maiores do que o indivíduo.

Nessa direção, Marimon e Vilarrasa apontam para o entendimento de que as concepções individuais do Amor são construções dependentes de elementos individuais e sociais, sendo influenciado tanto pelas características cognitivas e físicas do sujeito, de suas convicções, seu lugar no mundo, no tempo, no espaço e também pela linguagem, já que com essa "aprendemos a nomear as coisas ao mesmo tempo em que aprendemos como se deve olhá-las, ou seja, como devemos acreditar que são" (Marimon; VIlarrasa, 2014, p. 79). No mesmo sentido, John Money sugere que o Amor seja mais um "mapeamento" corporificado de crenças e práticas do sujeito do que um sentimento inato, sendo esses "mapas amorosos" (“lovemaps") repositórios de representações e padrões (mentais e cerebrais) que retratam e simbolizam o amor idealizado e o programa fantasiado de atividades erótico-sexuais com o Amor personificado. Para Money, os mapas amorosos são 
sempre constituídos por uma "credenda" (o arcabouço de crenças eideais do sujeito em relação ao Amor e à sexualidade) e por uma "agenda" (as práticas e meios de desempenhar seu Amor e sexualidade) (MoneY, 1988, p. 127-128). Ora, segundo Luhmann, o Amor não é sentimento a priori, e sim um código comunicativo subordinado às regras que formam sentimentos já condicionados socialmente (LuHMANN, 1998, p. 19-20). Assim, os mapas amorosos seriam como corporificações desse código comunicativo, influenciando as interações dos sujeitos envolvidos (e vice-versa). Conforme os autores acima citados, o Amor é dependente da linguagem, de concepções individuais e sociais, de idealizações, de fantasias, de práticas, etc., não autorizando entendê-lo como um fenômeno unitário exclusivamente sentimental.

Ainda que o Amor possa ser tanto um meio de comunicação quanto uma construção social, há algo de fugidio nele: para Roberto Mangabeira Unger (1998, p. 165-167), a paixão (e aqui ele inclui desejo, Amor, sexualidade, lascívia) precede a vida em sociedade, podendo ao mesmo tempo ser disruptiva e formadora de novos laços sociais, transbordando os limites impostos pelas instituições humanas. Entretanto, esses limites socialmente construídos para as paixões teriam paralelos com os próprios limites biológicos: para Damásio (2015) e Heller (1993), a homeostase - o ponto de equilíbrio de um organismo - limita os níveis de sentimentos permitidos. Além desse ponto, a própria sobrevivência do corpo está em risco: para Heller, a homeostase não é "meramente biológica", mas "social" (Heller, 1993, p. 33); já para Damásio, a homeostase é resultado de influências culturais e sociais externas (DAmasio, 2015, p. 53). Citando Heller: "Os sentimentos são regulados pelos costumes e ritos sociais de tal forma que o limite superior de intensidade socialmente prescrito e aceito, assim como seus conteúdos, não supere o limite tolerado pela homeostase biológica" (HeLler, 1993, p. 18; em livre tradução). Assim, o Amor com suas "credendas" e "agendas", torna-se, mesmo em seu nível mais impulsivo, determinado socialmente e enquadrado pela linguagem.

Para uma sociologia das sexualidades, portanto, o Amor pode ser entendido tanto como uma construção social quanto como forma de comunicação (e efeito da linguagem) com repercussões na carne, corporificando as visões sócio-históricas dos indivíduos e de suas narrativas pessoais, sendo indissociável, também, de suas vidas eróticas. Também é possível situar o Amor ao lado da sexualidade, ambos compreendidos como sistemas autônomos, nos quais os indivíduos acoplam seus sistemas psíquicos e biológicos. Ainda que o Amor e a sexualidade sejam dependentes de contextos pessoais, históricos e sociais, carregam algo de instintivo, podendo modificar ou renegar as normas desses contextos - porém, dentro de limites homeostáticos biológicos, que repercutem os limites sociais externos ao 
sujeito. Retorna-se, aqui, à tripla faixa de Mobius: não há limites precisos entre Amor, sexualidade, social, psíquico e biológico, e sim um movimento contínuo de influências mútuas.

\section{CONSIDERAÇ̃̃ES FINAIS}

Na contemporaneidade, ainda que diversos discursos especializados concorram por um lugar de verdade sobre a sexualidade humana, há um relativo consenso acerca da construção social do desejo erótico, do gênero, das orientações sexuais e da própria noção de prazer sexual e do corpo sexuado. Entretanto, ainda persistem os discursos essencialistas da sexualidade humana, que insistem na primazia da constituição biológica sobre as escolhas e afetos. Porém, de acordo com Fausto-Sterling "nenhuma disciplina acadêmica ou clínica nos fornece o melhor ou mais verdadeiro caminho para se entender a sexualidade humana" (FAusto-Sterling, 2000, p. 235), sendo que o biológico também se torna social e vice-versa, não sendo possível separar com rigor cientifico e cirúrgico as células, genes e hormônios das visões socialmente construídas da sexualidade humana em dada época e cultura.

Para ilustrar o fluxo contínuo entre o psíquico, o social e o biológico, foi utilizada neste artigo uma tripla faixa de Mobius, inserida em outra dupla, como uma topologia articuladora entre a Teoria dos Sistemas, o construcionismo e o essencialismo sexual. O sujeito, dessa forma, constitui-se em um contínuo de quatro sistemas: o social, o psíquico, o biológico e o indivíduo (isto é, o conjunto do sistema psíquico e biológico), sem direito nem avesso.

Entre os caminhos disponíveis - academicamente e clinicamente - para se entender a sexualidade humana, estão aqueles que conferem importância à linguagem, como o construcionismo social e a psicanálise. Entretanto, tal ênfase traz consigo provocações teóricas, como exemplificam os construcionistas Niklas Luhmann e Judith Butler: para o primeiro, o sujeito é apartado da sociedade, que se constitui de comunicações; para a segunda, o sujeito é impossibilitado de existir ou ser inteligível fora de marcos linguísticos preexistentes ao próprio sujeito.

As implicações dessas provocações teóricas, para uma sociologia da sexualidade, são diversas: de uma perspectiva sistêmica, encarar a sexualidade como um sistema autorreferente, autopoiético, enclausurado em si mesmo, formado por comunicações e apartado do sujeito, fornece maior autonomia a esse. Segundo a equação de Luhmann, “a Teoria dos Sistemas oferece mais possibilidades de pensar muito mais radicalmente a tendência ao individualismo" (LuHmann, 2009, p. 259). 
Porém, a partir de uma perspectiva butleriana, a sexualidade é uma construção linguística que se inscreve materialmente no corpo e na psique do sujeito, que por sua vez é moldado por marcos linguísticos preexistentes. Um denominador comum entre Butler e Luhmann, nessa medida, seria a primazia da linguagem sobre o sujeito e a sociedade: é por meio da linguagem que o sujeito surge, acopla-se e/ou autonomiza-se em relação aos sistemas da sexualidade, sendo capaz mesmo de se libertar de algumas contingências biológicas e sociais.

Por fim, é possível entender a sexualidade contemporânea como sistema complexo à parte do sujeito, com diversos subsistemas autopoiéticos, autorreferentes e cerrados operativamente, que visam reduzir a complexidade do entorno por meio de suas próprias diferenciações e seleções de elementos, além de construir suas próprias estruturas. Esses subsistemas traçam seus limites por meio de operações de sentido (para Luhmann, as comunicações; para Butler, os quadros linguísticos) e se acoplam ao sujeito, com repercussões sociais, biológicas e psíquicas. Butler e Luhmann convergem, assim, para um entendimento de que ao serem feitas distinções, os sistemas criam seus elementos, sendo que a distinção é o ato que faz seu oposto obrigatoriamente vir à tona. Com efeito, o abjeto é imprescindível ao ajustado, o homossexual ao heterossexual, etc. Dessa forma, olhar para uma sociologia da sexualidade pelas lentes de Butler e Luhmann confere, ao mesmo tempo, centralidade ao sujeito - já que é em seu corpo físico que são inscritos os códigos sociais que repercutem sob a forma de afetos e abjeções - e maior autonomia da sexualidade frente ao sujeito - acarretando maior reflexividade desse em relação aos sistemas da sexualidade. O sujeito pode, então, transitar entre esses sistemas e estar em constante construção e desestabilização ontológica. No entanto, entender a sexualidade como sistema apartado do sujeito tem implicações políticas, considerando que a sexualidade deixa de ser uma característica distintiva do sujeito para se tornar mais uma questão de escolha individual e de construção coletiva do que propriamente imposição biológica ou predisposição inata, contrariando discursos políticos que insistem na essencialização da sexualidade objetivando direitos civis.

Outra provocação teórica deste artigo se refere ao Amor que, junto com a sexualidade, é uma forma de comunicação orientada para as esferas orgânicas que "ajudam o organismo a falar" (Luhmann, 2010, p. 38). A Teoria dos Sistemas entende o Amor como forma de comunicação, fato social exterior ao sujeito, que se acopla a esse pela linguagem. Para Butler, "o Amor não é um estado, um sentimento, uma disposição, mas uma troca” (BUTLER, 2002, p. 65) e, pela perspectiva luhmanniana, uma troca comunicativa entre dois sistemas autônomos (os sujeitos 
envolvidos). Aqui, o Amor foi considerado mais como um mapeamento corporificado de crenças e práticas (Money, 1988), dependente das características físicas e cognitivas do sujeito (MARIMON; VILARRASA, 2014), do que como sentimento inato e biologicamente determinado, que é experimentado dentro de limites homeostáticos socialmente condicionados, além de ser enquadrado pela linguagem.

Importa, ainda, considerar o Amor como parte de uma sociologia da sexualidade, já que para Kulick e Cameron (2003) a sexualidade vai além das identidades sexuais, envolvendo toda espécie de afeto, desejo e de práticas eróticas, distanciando-a das "categorias 'objetivas' que os sociólogos criaram sobre a sexualidade humana” (FAUSTo-STERLING, 2000, p. 252). Sendo, portanto, tanto o Amor quanto a sexualidade apreendidas e que "aprendemos pelo corpo" (Bourdieu, 2001, p. 173), e sendo o corpo "o teatro de todas as emoções" (DAMAsio, 2015, p. 39), uma sociologia da sexualidade deve levar em conta tanto o corpo físico quanto a gama de sentimentos e emoções envolvidas na sexualidade, de modo a amplificar os níveis de análise - do intrapsíquico ao social -, já que tanto a sexualidade como os sentimentos são indistintamente psíquicos, biológicos e sociais. Ainda que, para Gaulejac (2013, p. 41), sejam "vãs as tentativas de uma metateoria na qual o psíquico e o social sejam englobados em um só conjunto", para pensar a sexualidade contemporânea impõe-se não privilegiar o corpo sobre o social, tampouco o social sobre o psíquico, nem o psíquico sobre o corpo; mas sim entender esses elementos como um continuum que acabaria por configurar o próprio sujeito.

Por fim, não se deve negligenciar as narrativas pessoais a respeito do Amor e da sexualidade, de modo a entendê-los enquanto sistemas, no sentido luhmanniano, e como formas de comunicação que fazem o indivíduo corporificar concepções de Amor e sexualidade de seu lócus socioespacial, colaborado na própria construção do sujeito. Uma sociologia da sexualidade pode se apoderar de ferramentas teóricas e empíricas úteis para empreender o estudo mais holístico das relações sexuais e afetivas humanas.

\section{REFERÊNCIAS BIBLIOGRÁFICAS}

ADELMAN, Miriam. Sexo, gênero, sujeito: uma entrevista com Alain Touraine. Revista de Sociologia e Política, Curitiba, v. 23, p. 169-174, 2004.

ARCHER, Margareth. Being Human: The problem of agency. Cambridge: Cambridge University Press, 2000.

BECH, Henning. When men meet: homosexuality and modernity. Cambridge: Polity, 1997. 
BECK, Ulrich; GIDDENS, Anthony; LASH, Scott. Modernização reflexiva. São Paulo: Unesp, 1997.

BERING, Jesse. Devassos por natureza: provocações sobre sexo e a condição humana. Rio de Janeiro: Jorge Zahar, 2013.

BOZON, Michel. Sociologia da Sexualidade. Rio de Janeiro: FGV Editora, 2004.

BOURDIEU, Pierre. Meditações pascalianas. Rio de Janeiro: Bertrand do Brasil, 2001.

BUTLER, Judith. Bodies that matter: on the discursive limits of sex. Nova York: Routledge, 1993.

"Doubting Love". In. HARMON, James L. (Org.). Take my advice: letters to the next generation from people who know a thing or two. New York: Simon \& Schuster, 2002, p. 62-66.

BRADY, Anita; SCHIRATO, Tony. Understanding Judith Butler. Londres: SAGE, 2011.

CAMERON, Deborah; KULICK, Don. Language and sexuality. Cambridge: Cambridge University Press, 2003.

CANDLAND, Douglas K. Feral children and clever animals: reflections on human nature. Oxford: Oxford University Press, 1995.

COLLINS, Randall. Interaction ritual chains. Princeton: Princeton University Press, 2004. COZOLINO, Louis. The Neuroscience of Human Relationships: Attachment and the Developing Social Brain (Norton Series on Interpersonal Neurobiology). New York: WW Norton \& Company, 2014.

DAMASIO, Antonio. O mistério da consciência: do corpo às emoções ao conhecimento de si. São Paulo: Companhia das Letras, 2015.

DAVIS, Kingsley. "Extreme Isolation”. In. HENSLIN, James M. (Org.). Down to earth sociology: introductory readings. Nova York: Simon and Schuster, 2007, p. 151-159.

DE GAULEJAC, Vincent. O âmago da discussão: da sociologia do indivíduo à sociologia do sujeito. Revista Cronos, Natal, v. 5, n. 1/2, p. 59-77, 2013.

DELANY, Samuel R. Times Square red, Times Square blue. New York: New York University Press, 1999.

DABHOIWALA, Faramerz. As origens do sexo. Rio de Janeiro: Globo Livros, 2013.

ELIAS, Norbert. A Sociedade dos Indivíduos. Rio de Janeiro: Jorge Zahar, 1993.

EPSTEIN, Steven. "A queer encounter: sociology and the study of sexuality”. In. SEIDMAN, Steven (Org.). Queer Theory/Sociology. Cambridge: Blackwell, 1996.

FAUSTO-STERLING, Anne. Sexing the body: gender politics and the construction of sexuality. Nova York: Basic Book, 2000.

GAGNON, Jonh H.; SIMON, William. Sexual conduct: the social sources of human sexuality. New Jersey: Transaction publishers, 2011.

GHIRALDELLI JR., Paulo. O corpo: filosofia e educação. São Paulo: Ática, 2007. 
GIDDENS, Anthony. A transformação da intimidade: sexualidade, amor e erotismo nas sociedades modernas. São Paulo: Unesp, 1993.

"A vida em uma sociedade pós-industrial". In. BECK, Ulrich; GIDDENS, Anthony; LASH, Scott. Modernização reflexiva. São Paulo: Unesp, 1997, p. 73-134. . Sociologia. Porto Alegre: Penso, 2012.

GREEN, Adam Isaiah (Org.). Sexual Fields: Toward a sociology of collective sex life. Chicago: Chicago University Press, 2014.

GROSZ, Elizabeth. Volatile bodies: towards a corporeal feminism. Indianapolis: Indiana University Press, 1994.

Architecture from the outside: Essays on virtual and real space. Cambridge, MA: MIT Press, 2001.

HARMON, James L. (Org.). Take my advice: letters to the next generation from people who know a thing or two. New York: Simon \& Schuster, 2002.

HAWKES, Gail. A Sociology of sex and sexuality. Philadelphia: Open University Press, 1996.

HELLER, Agnes. Teoría de los sentimientos. Barcelona: Fontamara, 1993.

HONNETH, Axel. Luta por reconhecimento: a gramática moral dos conflitos sociais. São Paulo: Editora 34, 2003.

HENSLIN, James M. (Org.). Down to earth sociology: introductory readings. Nova York: Simon and Schuster, 2007.

HUNT, Lynn Avery (Org.). The invention of pornography: obscenity and the origins of modernity, 150o-180o. New York: Zone Books, 1996.

IZUQUIZA, Ignacio. La sociedad sin hombres: Niklas Luhmann o la teoria como escàndalo. Barcelona: Anthropos, 2008.

LACAN, Jacques. O Seminário-Livro II: os quatro conceitos fundamentais da psicanálise. Rio de Janeiro: Jorge Zahar, 1988.

LASH, Scott. "A reflexividade e seus duplos: estrutura, estética, comunidade”. In. BECK, Ulrich; GIDDENS, Anthony; LASH, Scott. Modernização reflexiva. São Paulo: Unesp, 1997, p. 135-206.

LEHMAN, Peter. Running scare: masculinities and the representation of male body. Detroit: Wayne State University Press, 2007.

LUHMANN, Niklas. Love as passion: the codification of intimacy. Cambridge, MA: Harvard University Press, 1998. . Introdução à teoria dos sistemas. Petrópolis: Vozes, 2009. Love: a sketch. Cambridge: Polity, 2010.

MARIMÓN, Montserrat Moreno; VILARRASA, Genoveva Sastre. Como construímos universos. São Paulo: Editora UNESP, 2014. 
MLODINOW, Leonard. Subliminar: como o inconsciente influencia nossas vidas. Rio de Janeiro: Jorge Zahar, 2013.

MONEY, John. Gay, straight, and in-between: The sexology of erotic orientation. Oxford: Oxford University Press, 1988.

NEWTON, Michael. Savage girls and wild boys. London: Faber \& Faber, 2002.

RASCH, William. Niklas Luhmann's Modernity: The paradoxes of differentiation. Redwood: Stanford University Press, 2000.

RODRIGUES, Leo Peixoto; NEVES, Fabrício. Niklas Luhmann: a sociedade como sistema. Porto Alegre: Edipucrs, 2012.

SCOTT, Jonh (Org.). Sociologia: conceitos-chave. Rio de Janeiro: Jorge Zahar, 2010.

SEIDMAN, Steven (Org.). Queer Theory/Sociology. Cambridge: Blackwell, 1996.

SIMMEL, Georg. Questões fundamentais da sociologia. Rio de Janeiro: Zahar, 2006.

SALIH, Sara. Judith Butler e a Teoria Queer. Belo Horizonte: Autêntica, 2012.

UNGER, Roberto Mangabeira. Paixão: um ensaio sobre a personalidade. São Paulo: Boitempo, 1998.

ZINGG, Robert M. Feral man and extreme cases of isolation. The American Journal of Psychology, v. 53, n. 4, p. 487-517, 1940.

WEBER, Max. Economia e Sociedade. Volume 1. Brasília: Editora UnB, 2012.

Recebido para publicação em 07/05/2015. Aceito para publicação em 10/09/2015. 